This is the author's final, peer-reviewed manuscript as accepted for publication. The publisher-formatted version may be available through the publisher's web site or your institution's library.

\title{
Parasitism interacts with mutual interference to limit foraging efficiency in larvae of Nephus includens (Coleoptera: Coccinellidae)
}

Mohamed H. Bayoumy, J. P. Michaud

\section{How to cite this manuscript}

If you make reference to this version of the manuscript, use the following information:

Bayoumy, M. H., \& Michaud, J. P. (2012). Parasitism interacts with mutual interference to limit foraging efficiency in larvae of Nephus includens (Coleoptera: Coccinellidae). Retrieved from http://krex.ksu.edu

\section{Published Version Information}

Citation: Bayoumy, M. H., \& Michaud, J. P. (2012). Parasitism interacts with mutual interference to limit foraging efficiency in larvae of Nephus includens (Coleoptera: Coccinellidae). Biological Control, 62(2), 120-126.

Copyright: () 2012 Elsevier Inc.

Digital Object Identifier (DOI): doi:10.1016/j.biocontrol.2012.04.001

Publisher's Link: http://www.sciencedirect.com/science/article/pii/S1049964412000783

This item was retrieved from the K-State Research Exchange (K-REx), the institutional repository of Kansas State University. K-REx is available at http://krex.ksu.edu 
Bayoumy and Michaud: Foraging efficiency of parasitized Nephus includens

Journal of Biological control
M. H. Bayoumy

Entomology Department

Faculty of Agriculture

Mansoura University

Mansoura 35516, Egypt

Phone: 0020147675322

Email: marsamarium@yahoo.com

mansourauniv@yahoo.com

\title{
Parasitism Interacts with Mutual Interference to Limit Foraging Efficiency in Larvae of Nephus includens (Coleoptera: Coccinellidae)
}

\author{
Mohamed H. Bayoumy ${ }^{1}$ and J. P. Michaud ${ }^{2}$
}

${ }^{1}$ Economic Entomology Department, Faculty of Agriculture, Mansoura University, Mansoura 35516, Egypt.

${ }^{2}$ Kansas State University, Agricultural Research Center-Hays, 1232 240th Ave, Hays, Kansas 67601, USA. 
ABSTRACT Predator parasitism can modify predator-prey interactions through long-term (numerical) and short-term (functional response) impacts. However, mutual interference is another density-dependent factor that may affect predator foraging efficiency in the presence or absence of parasitism. This study examined the effects of parasitism of the invader Nephus includens (Kirsch) (Coleoptera: Coccinellidae) by Homalotylus flaminius Dalman (Hymenoptera: Encyrtidae), predator density, and prey density on the searching efficiency (a measure of area of discovery) using the cotton aphid, Aphis gossypii Glover (Hemiptera: Aphididae) as prey. Mutual interference reduced foraging efficiency by $47 \%$ in parasitized fourth-instar larvae compared to $44 \%$ in those unparasitized. Increasing predator density decreased searching efficiency more markedly in parasitized than in unparasitized larvae. The combined effects of parasitism and mutual interference reduced searching efficiency by $91 \%$.

Conversely, prey consumption by parasitized fourth-instar larvae increased with increasing prey density. Interference values declined from 0.98 to 0.82 with increasing prey density, indicating that the negative effect of parasitism on predator foraging diminished with increasing prey availability. Thus, these results support the inference of the 'enemy release' hypothesis, that invading predators may be more successful and have higher impacts on prey when they escape from parasitism. In the context of augmentation of $N$. includens against A. gossypii on guava in Egypt, releases of predator life stages immune to parasitism by $H$. flaminius (e.g., pupae or adults) in a suitable predator-prey ratio should minimize the negative effects of parasitism and intraspecific interference, and thus maximize efficiency of the predator against the pest.

KEY WORDS area of discovery, functional response, Homalotylus flaminius, intraspecific competition, predation, searching efficiency

\section{Introduction}


Invasive species can have profound impacts on invaded communities because they generate new trophic relationships, sometimes at the expense of autochthonous species. However, parasitism of the invasive species has the potential to attenuate these impacts Dunn, 2009). Parasitism can drive changes in trophic interactions between other species and has the potential to alter broader community processes through long-term effects on densities of predators or their prey (Wilmers et al., 2006). There is also growing interest in short-term, 'trait-mediated indirect effects' of parasitism on predator-prey interactions (Hatcher et al., 2008). For example, parasitoid behavioral manipulation of hosts can lead to their increased vulnerability to predation (Lafferty, 1992; Shi et al., 2002; Dick et al., 2010).

The cotton aphid, Aphis gossypii Glover (Hemiptera: Aphididae), is a cosmopolitan plant pest of tropical, subtropical and warm temperate regions. It attacks hundreds of plant species and vectors at least 76 plant viruses (Chan et al., 1991). In Egypt, pesticides have been widely used for cotton aphid control in fruit and vegetable crops, especially guava, Psidium guajava L. (Abd El-Gawad and El-Zoghbey, 2009). However, the evolution of insecticide resistance and growing concerns of the environmental hazards of frequent insecticide applications have prompted more emphasis on biological control of aphids (van Emden and Harrington, 2007), especially the use of predators (Sarmento et al., 2007). For example, the predatory gall midge, Aphidoletes aphidomyza Rondani has been employed successfully for aphid control in cucumber culture (Bennison and Corless, 1993).

Coccinellid beetles are an important group of predatory insects with considerable biocontrol potential against aphids and other pest species (Hodek and Honek, 1996; Michaud, 2012). They feed on a wide range of prey, tend to be very voracious, and can exhibit rapid numerical responses (Hodek and Honěk, 1996; Bayoumy, 2011b). However, they do not always maintain 
prey populations in check (Northfield et al., 2010; Michaud, 2012). Thus, evaluations of particular aphidophagous species in specific agronomic situations are needed to assess their biological control potential. The lady beetle Nephus includens (Kirsch) (Coleoptera: Coccinellidae) is a primarily coccidophagous species of Palearctic origin and an effective predator of some agriculturally important mealybugs in Greece (Argyriou et al., 1976). It has fortuitously established in Egypt where it has been recently found preying on mealybugs (AbdelSalam et al., 2010). Nephus includens has been studied as a predator of the citrus mealybug, Planococcus citri (Risso) and its biological performance on that species has been assessed in Italy (Tranfaglia and Viggiani, 1972). The life table parameters of $N$. includens also have been studied on other mealybug species (e.g., Canhilal et al., 2001; Al-Khateeb and Asslan, 2007; Abdel-Salam et al., 2010). Although alternative prey species have not been thoroughly catalogued for $N$. includens, it has been observed in Egypt feeding on the cotton aphid A. gossypii (Bayoumy, 2011b). Thus, relatively little is yet known of this species' biology or ecology in Egypt.

The thelytoky parasitoid, Homalotylus flaminius Dalman (Hymenoptera: Encyrtidae) is a solitary, koinobiont endoparasitoid attacking the second-instar larvae of several species of coccinellids, including N. includens (Novin et al., 2000; Ma and Lin, 2001; Abdel-Salam et al., 2010). The genus Homalotylus comprises the most important parasitoids of Coccinellidae with about 50 species worldwide (Noyes, 2005). Homalotylus sinensis Xe and Hu has been reported as a larval parasitoid of Nephus bipunctatus (Kugelann) from Iran (Fallahzadeh et al., 2006). Up to $90-95 \%$ of larvae of the coccinellid Chilocorus bipustulatus L. have been parasitized by $H$. flaminius in North Africa and the Black Sea region (Rubtsov, 1954; Majerus, 1994). The foraging behavior and predatory efficiency of coccinellids may be affected by many factors 
including their developmental stage (Koch et al., 2003), body size (Kajita and Evans, 2010), the prey species (Sarmento et al., 2007), prey density (Matter et al., 2011), temperature (Skirvin et al., 1997), foraging cues (Hodek and Honěk, 1996; Pasteels, 2007), plant architecture (Grevstad and Klepetka, 1992), cannibalism and intraguild predation (Burgio et al., 2002), food deprivation (Santos-Cividanes et al., 2011), and entomopathogenic fungi (Poprawski et al., 1998). However, few studies have yet examined the potential impact of larval parasitism on coccinellid foraging behavior. Bayoumy (2011b) assessed the effect of $H$. flaminius parasitism of $N$. includens larvae by deriving functional responses for parasitized second- and fourth-instars preying on A. gossypii at different prey densities. Although, parasitism did not alter the type of response in earlyparasitized second-instar $N$. includens, it adversely affected the response of fourth instars, ostensibly due to the more advanced age of the parasitoid larva. Unparasitized fourth-instars were observed to be the most voracious stage with the highest attack rate and lowest handling time, and thus were selected for use in the current study.

One of the most informative methods for studying the predator-prey interaction involves measuring functional response and searching efficiency as these often correlate with biocontrol efficacy (Pervez and Omkar, 2005; Fathipour et al., 2006; Bayoumy, 2011b). Various models have been proposed to describe the interactions of one prey with one predator, beginning with the Lotka-Volterra model (Lotka, 1925; Volterra, 1926). However, models for the interaction of more than two species, for example, predator-prey interactions with parasitism as an additional factor, have been less studied because more complex phenomena arise (Freedman and Waltman, 1985).

In many cases, parasitism modifies the external features of an organism or its behavior to render it more vulnerable to predation (e.g., Lafferty, 1992; Shi et al., 2002). Although 
parasitized animals often exhibit a reduction in food consumption (e.g., Arnott et al., 2000; Wright et al., 2006), parasitism may also trigger an increase in consumption (Slansky and Scriber, 1985; Dick et al., 2010). Thus, counterintuitively, parasitism might increase the competitive ability and/or functional response of invading predators. In the context of previous work on the invasive $N$. includens, (Bayoumy, 2011b), here we compared the searching efficiency of parasitized and unparasitized individuals to infer likely consequences of parasitism for population and community processes. A secondary objective was to test whether intraspecific interference would interact with parasitism via effects on predator consumption rates. Specifically, this work aimed to investigate (1) the impact of parasitism by H. flaminius on the searching efficiency of fourth-instar $N$. includens and its interaction with predator density (i.e., mutual interference) and (2) the effect of various predator-prey density combinations on searching efficiency and mutual interference values for parasitized fourth-instar $N$. includens.

\section{Materials and methods}

\subsection{Insect cultures and general experimental conditions}

A colony of $N$. includens was established from pupae collected on guava trees, Psidium guajava L. at the experimental Farm, Faculty of Agriculture, Mansoura University at Mansoura district, Egypt during 2010-spring season. These trees were infested with Icerya seychellarum Westwood, Planococcus citri Risso and A. gossypii. Pupae $(\mathrm{n}=96)$ were placed in Petri dishes $(6.0 \mathrm{~cm}$ diameter $\times 2.0 \mathrm{~cm}$ height, $\mathrm{n}=6 /$ dish $)$ lined with filter paper and transported to the laboratory. Pupae were maintained at $25 \pm 1^{\circ} \mathrm{C}$ and a photoperiod of $16: 8 \mathrm{~h}$ (L:D) in a climatecontrolled incubator until emergence of adults $(\mathrm{n}=58)$. Adults were sexed based on the color of 
the ventral abdominal surface, which is darker in females. Predator pairs $(n=26)$ were isolated in Petri-dishes $(9.0 \mathrm{~cm}$ diameter $\times 1.6 \mathrm{~cm}$ height $)$ containing guava leaves with ad libitum prey (A. gossypii) under the same physical conditions to permit mating. Leaves were examined daily for eggs and the male was removed at first oviposition. Each female was allowed to oviposit for $24 \mathrm{~h}$ on aphid-infested leaves in the Petri-dish and was then transferred to a new dish. Eggs laid on the leaves were maintained under the same physical conditions (as above) for 2-3 days until eclosion. The petiole of each leaf was encased in a water-saturated cotton ball to maintain its condition. Eclosing larvae were reared individually and supplied daily with ad libitum aphids until they reached stages required for use in the experiments. Observations were made at $24 \mathrm{~h}$ intervals to select the desired instars.

A colony of $H$. flaminius was established from the parasitized fourth instar $N$. includens collected from aphid-infested guava trees at the above-mentioned Experimental Farm. Each parasitized larva was isolated in a $5 \mathrm{ml}$ Eppendorf tube (Eppendorf Gerätebau Netheler \& Hinz GmbH, Oldenburg, Germany). Tube caps were perforated with a pin to provide ventilation and each was supplied daily with aphids ( $\approx 40$ nymphs) on a small piece of guava leaves until larvae mummified. Upon emergence of adult parasitoids, 30 females (48-96 h old) of the thelytokous wasp were released in Petri-dishes $(9.0 \mathrm{~cm}$ diameter $\times 1.6 \mathrm{~cm}$ height $)$ containing second-instar $N$. includens larvae (3 females/10 larvae/dish) for five hours. A diluted honey solution was provided on a cotton wick. Host larvae were parasitized in this manner in one-day intervals to obtain a staggered emergence of adult parasitoids for the following generation. Exposed larvae were reared individually in Eppendorf tubes under the afore-mentioned physical conditions until emergence of adults. The adults were maintained in Eppendorf tubes and supplied with diluted honey until used in the experiments. 


\subsection{Preparation of parasitized larvae}

To study the effect of parasitism on the searching efficiency of fourth instars, a series of second instars [the preferred instar for parasitism by H. flaminius (Majerus, 1994)] were parasitized. Second-instar larvae were placed in $9.0 \mathrm{~cm}$ Petri-dishes (4 dishes, 10 larvae/dish) containing a surplus of aphids on guava leaves. Three to five $H$. flaminius females (48-96 h old) were released into each of three dishes for a period of five hours with food provided as described above; larvae in the fourth dish were held without parasitoids to serve as controls. Larvae in each dish were reared with an ad libitum supply of aphid prey until they molted to the fourth instar. Only fourth instar larvae which showed evidence of parasitism were selected for the experiment. Parasitized larvae are recognizable in the fourth instar by the presence of darkened abdomenal coloration, partial absence of wax filaments that normally extend from dorsal epidermis, and elongation of the abdominal segments.

\subsection{Effect of parasitism, mutual interference, and prey density on area of discovery}

Newly molted fourth-instar larvae $(<24 \mathrm{~h}$ old, both parasitized and unparasitized) were starved for $6 \mathrm{~h}$ before each experiment to standardize hunger levels. To measure the differences in consumption rates due to the influence of parasitism and mutual interference on searched larvae of the predator, the larvae of both parasitized and unparasitized were grouped in treatments of one, two, three, four, or five individuals per Petri-dish, each containing a guava leaf

on which 85 A. gossypii nymphs $\left(2^{\text {nd }}\right.$ and $3^{\text {rd }}$ instars $)$ were feeding. Nephus includens larvae and A. gossypii nymphs were held together for $24 \mathrm{~h}$. After $24 \mathrm{~h}$., the larvae were removed and the aphids remaining in the dish were counted to determine the number consumed. The experiment was replicated 7-10 times simultaneously. 
To assess the area of discovery of parasitized fourth instar $N$. includens as a function of preypredator density, three prey densities $\left(70,85\right.$, and $1002^{\text {nd }}-3^{\text {rd }}$ instar aphids/patch) were tested with five densities of parasitized fourth-instar predators $(1,2,3,4$, and 5 /patch) under the same conditions as described above. The experiments were replicated 6-7 times simultaneously. To estimate the rate of natural prey mortality in the absence of predation, control arenas were established that contained the same aphid-infested leaves without predators. Prey mortality in treatment arenas was adjusted downward by the mean prey mortality observed in control arenas.

In order to estimate the area of discovery of the predator we used Hassell (1978) as follows:

$$
a_{t}=1 / P \log _{e} N / N-N_{a}
$$

where $a$ is the area of discovery, $t$ the time of exposure (1 day), $N$ the prey density, $N_{a}$ the number of prey consumed, and $P$ the predator density.

The above model (1) was used to correlate the area of discovery to prey density, but was inappropriate for correlation with predator density, as it assumes each parasitized host gives rise to a new parasitoid, which is not true in a predator-prey system. Moreover, given that the area of discovery is not constant and there is mutual interference among predators, the model of Hassell and Varley (1969) was used as follows:

$$
a_{t}=Q P^{-m}
$$


where $a$ is the area of discovery, $Q$ the quest constant (area of discovery with one predator searching), $m$ the mutual interference constant (slope of regression of $\log a_{t}$ on $\log P$ ), and $P$ the predator density; the equation becomes linear as follows:

$$
\log _{a t}=\log Q-m \log P
$$

\subsection{Data analysis}

The effect of predator density and parasitism status on number of prey consumed by the unparasitized and parasitized fourth-instar predators was subjected to a two-way ANOVA with predator density and parasitism as fixed factors. In the event of a significant interaction, a separate one-way ANOVA was conducted to test the effect of predator density on the number of

prey consumed. Means were separated by Tukey's test when data were normally distributed and variances were homogeneous (Barltett's test for equal variances). The number of prey consumed by $N$. includens larvae at each predator density was analyzed using an independent sample $t$ test.

Prey consumption by parasitized fourth-instar larvae was subjected to a two-way ANOVA with prey density and predator density as fixed factors. In the event of a significant interaction, separate one-way ANOVAs were conducted for each prey density to test the effect of predator density on the number of prey consumed by parasitized larvae. Similarly, one-way ANOVAs were conducted at each predator density to test the effect of prey density on the number of prey consumed. Means were separated by Tukey's test. Statistics were performed with Graph Pad Prism three (GraphPad, 1999).

The relationships between predator density and area of discovery for both parasitized and unparasitized fourth instar larvae, and between the area of discovery for parasitized larvae and 
predator density at various prey densities, were analyzed by linear regression by using Graph Pad Prism three (GraphPad, 1999).

\section{Results}

There were significant effects of predator density $(F=4.33$; df $=4,73 ; P<0.001)$ and parasitism $(F=226.6 ; \mathrm{df}=1,73 ; P<0.0001)$ on the number of prey consumed, and the interaction between these main effects was significant $(F=4.88 ; \mathrm{df}=4,73 ; P<0.001)$. Aphid consumption by both parasitized and unparasitized fourth-instar larvae increased as predator density increased $(F=5.62 ; \mathrm{df}=4,36 ; P<0.001$ and $F=10.67 ; \mathrm{df}=4,36 ; P<0.0001$, respectively). However, prey consumption per predator decreased significantly as predator density increased (parasitized: $F=464.18$; $d=4,36 ; P<0.0001$; unparasitized: $F=123.42$; df $=$ 4,36; $P<0.0001 ;$ Table 1). There were significant differences in the number of prey consumed by parasitized and unparasitized larvae at each predator density (one predator: $t=5.16, P<$ 0.0001; two predators: $t=6.53, P<0.0001$; three predators: $t=9.2, P<0.0001$; four predators: $t$ $=15.29, P<0.0001$; and five predators: $t=14.31 ; P<0.0001)$. Similarly, there were significant differences between parasitized and unparasitized larvae in the number of prey consumed per individual at each predator density (Table 1).

Both prey density and predator density had significant effects on consumption by parasitized $N$. includens larvae $(F=159.8 ; \mathrm{df}=2,94 ; P<0.0001$ and $F=24.54 ; \mathrm{df}=4,94 ; P<0.0001$, respectively). There was also a significant prey density* predator density interaction on total prey consumption $(F=2.23 ; \mathrm{df}=8,94 ; P<0.05)$ and significant differences in consumption at each predator density (one predator: $F=16.49$; $\mathrm{df}=2,18 ; P<0.0001$; two predators: $F=19.86$; df= 
2,$16 ; P<0.0001 ;$ three predators: $F=67.87 ; \mathrm{df}=2,16 ; P<0.0001$; four predators: $F=35.36$; $\mathrm{df}$ $=2,16 ; P<0.0001$; and five predators: $F=45.68 ; \mathrm{df}=2,16 ; P<0.0001)$. Similarity, there were significant differences in prey consumption by parasitized larvae at each prey density (70 nymphs/patch: $F=3.36 ; \mathrm{df}=4,25 ; P<0.01 ; 85$ nymphs/patch: $F=5.62 ; \mathrm{df}=4,32 ; P<0.001$; and 100 nymphs/patch: $F=18.71 ; \mathrm{df}=4,25 ; P<0.0001$; Table 2$)$.

At a constant prey density, the area of discovery for parasitized larvae decreased more steeply as predator density increased when compared to that of unparasitized larvae. The decrease in the area of discovery was curvilinear in relation to predator density for both parasitized and unparasitized larvae, with the highest values $(0.35 \pm 0.02$ and $0.63 \pm 0.22$, respectively) observed with one predator foraging and the lowest $(0.081 \pm 0.009$ and $0.31 \pm 0.09$, respectively) with five predators foraging (Fig. 1). Mutual interference values estimated by equation 5 were higher for parasitized larvae $(m=-0.92)$ than for unparasitized $(m=-0.44)$. In contrast, the quest constants (i.e., level of efficiency) were higher for unparasitized $(Q=0.45)$ than for parasitized larvae $(Q=0.23$; Fig. 2$)$. There was also a curvilinear decrease in the area of discovery across prey densities with increasing predator density when predators foraged for 70 , 85, and $100 \mathrm{prey} / \mathrm{patch}$, the highest values $(0.39 \pm 0.04,0.35 \pm 0.02$ and $0.31 \pm 0.02$, respectively) being obtained when a single predator foraged and the lowest $(0.08 \pm 0.03,0.081 \pm$ 0.009 and $0.084 \pm 0.005$, respectively) when five predators foraged (Fig. 3). Thus, mutual interference values for parasitized larvae decreased with increasing prey density, while their level of efficiency (Q) increased (Fig. 4).

\section{Discussion}


The present study illustrates that parasitism of a predator can modify predator-prey interactions via short-term density-dependent effects on predator foraging behavior, i.e. the functional response and searching efficiency. Prey consumption by unparasitized larvae increased with their density, implying that high release rates of predators would increase rates of prey consumption. However, increasing the number of predators in the patch did not result in a proportional increase in the number of prey consumed, due to the negative effects of mutual interference. The observed decrease in the searching efficiency (area of discovery) as a function of increasing predator density suggests that mutual interference among predators increased steeply at higher predator densities. This is likely due, at least in part, to confinement in the experimental arena that generated high conspecific encounter rates. Clearly, empirical data obtained under laboratory conditions cannot be directly extrapolated to field conditions, but the data suggest that predator aggregation in a specific prey patch will increase negative conspecific interactions. As the density of conspecifics increases, each predator spends less time searching for prey and more time interacting with conspecifics (Hassell, 1971), and this explains why searching efficiency declined as predator density increased. On the other hand, prey consumption by unparasitized and parasitized larvae was unequally affected at various predator densities, owing to the negative effects of both parasitism and mutual interference. Although both factors reduced predation efficiency, they also interacted. The combined effect of both factors contributed to a $91 \%$ reduction in the area of discovery at the highest predator density; parasitism alone reduced searching efficiency by $47 \%$ (i.e., $m$ parasitized- $m$ unparasitized $=0.91-0.44$ ), whereas high predator density further reduced efficiency by $44 \%$. Therefore, parasitism increased the negative effect of intraspecific competition on foraging efficiency, and thus has the potential to diminish predator functional response under field conditions, in addition to the obvious longer-term 
impact on predator numerical response. There are few studies of parasitism impact on predator foraging behavior. For example, Dick et al. (2010) demonstrated that parasitism of a predatory amphipod, Gammarus pulex (L.), enhanced its predation rate on the crustacean, Asellus aquaticus (L.). However, this is not an analogous situation because the acanthocephalan parasite in this case, Echinorhynchus truttae, has only modest impact on the fitness of its host, whereas insect parasitoids are ultimately lethal.

Although parasitized fourth-instar predators consumed more prey as prey density increased, the highest area of discovery was observed at the lowest prey density (i.e., 70 prey/patch). The apparent anomaly of the highest area of discovery (greatest searching efficiency) occurring at the lowest prey density (which also generated the greatest mutual interference) explains the significant interaction between prey and predator densities. However, the quest constant $Q$ (i.e., the level of efficiency) increased with prey density and the corresponding reduction in mutual interference (Fig. 4). Thus, increased food availability may reduce the effect of intraspecific competition and increase the consumption rate of parasitized larvae. It is also possible that the predator spends more time handling each prey item when they are at low density, and handling time is greater for parasitized larvae (Bayoumy, 2011b). Whereas a positive association between feeding rate and oviposition rate will enhance aggregation, mutual interference between predators will reduce foraging efficiency as aggregation increases (Eveleigh and Chant, 1982), resulting in a trade-off between the costs and benefits of aggregating (van der Meer and Ens, 1997). In the present study, parasitism had more impact on the searching efficiency at high predator densities and low prey densities. Thus, as prey density increases, the effect of interference is diminished along with the disadvantage of parasitism. This may explain why both 
area of discovery and intraspecific interference for parasitized individuals level off at high prey densities.

Data on predation rates under pressure of parasitism and in relation to crowding and prey availability are useful for forecasting the role of $N$. includens as a biological control agent. Although laboratory data require corroboration with field studies, these results demonstrate that predation by $N$. includens larvae can be dramatically influenced by parasitism and mutual interference. In particular, the effect of predator-prey ratios on predation rates warrant careful evaluation in other studies, since food availability and size of the experimental arena are expected to strongly influence mutual interference. In the context of augmentation biological control, carefully timed releases of $N$. includens life stages that are immune to parasitism (e.g., pupae or adults) in a suitable predator-prey ratio could aid in minimizing the detrimental effects of parasitism and intraspecific interference on foraging behavior, thus enhancing predator efficacy.

\section{Acknowledgments}

The authors appreciate the careful review and linguistic improvements on the manuscript by Stephen L. Lapointe (Subtropical Insects Research Unit, U.S. Horticultural Research Laboratory USDA/ARS, U.S.A.), B. Kaydan (Department of Plant Protection, University of Yuzuncu Yil, 65080 Van, Turkey), and A. H. Abdel-Salam (Economic Entomology Department, Faculty of Agriculture, Mansoura University, Egypt) and two anonymous reviewers. The authors also thank A. S. Hendawy (Agriculture Research Center, Plant Protection Research Institute, 
Cairo, Egypt) for identifying parasitoid specimens and to the following postgraduate students, Marwa Mahmoud and Amera Abdel-Hady for providing with aphid populations.

\section{References}

Abd El-Gawad, H.A.S., El-Zoghbey, A.A.A., 2009. Use the Coccinella undecimpunctata L. for controlling Aphis gossypii Glover and Myzus persicae (Sulzer) on cucumber in Egypt. Egypt. Academic Journal of Biological Sciences 2, 81-85.

Abdel-Salam, A.H., Ghanim, A.A., Awadalla, H.S., 2010. Biological attributes and life table parameters of Nephus includens (Kirsch) (Coleoptera: Coccinellidae) as a natural enemy of margarodid mealybugs in Egypt. Journal of Plant Protection and Pathology 1, 51-62.

Al-Khateeb, N., Asslan, L., 2007. Study and determination of the most important biological parameters of the predator, Nephus includens (Kirch) and comparison with parameters of the famous introduced predator, Cryptolaemus montrouzieri Mulsant. Journal of Agricultural Sciences 23, 121-134.

Argyriou, L.C., Stavraki, H.G., Mourikis, P.A., 1976. A list of recorded entomophagous insects of Greece. Benaki Phytopthological Institute, Athens, Greece.

Arnott, S.A., Barber, I., Huntingford, F.A., 2000. Parasite associated growth enhancement in a fish-cestode system. Proceedings of the Royal Society, London Ser B 267, 657-663.

Bayoumy, M.H., 2011a. Functional response of the aphelinid parasitoid, Aphytis diaspidis: The effect of host scale species, Diaspidiotus perniciosus and Hemiberlesia lataniae. Acta Phytopathologica et Entomologica Hungarica 46, 101-113. 
Bayoumy, M.H., 2011b. Foraging behavior of the coccinellid Nephus includens (Coleoptera: Coccinellidae) in response to Aphis gossypii (Hemiptera: Aphididae) with particular emphasis on larval parasitism. Environmental Entomology 40, 835-843.

Bennison, J.A., Corless, S.P., 1993. Biological control of aphids on cucumbers: further development of open rearing units or banker plants to aid establishment of aphid natural enemies. Bull IOBC/WPRS 16, 5-8.

Burgio, G., Santi, F., Maini, S., 2002. On intraguild predation and cannibalism in Harmonia axyridis Pallas and Adalia bipunctata L. (Coleoptera Coccinellidae). Biological Control 24, $110-116$.

Canhilal, R., Uygun, N., Carner, G.R., 2001. Effects of temperature on development and reproduction of a predatory beetle, Nephus includens Kirsch (Coleoptera: Coccinellidae). Journal of Agriculture and Urban Entomology 18, 117-125.

Chan, C.K., Forbes, A.R., Raworth, D.A., 1991. Aphid transmitted viruses and their vectors of the world. Agriculture Canada Research Branch Technology Bulletin 3E, 1-216.

Dick, J.T.A., Armstrong, M., Clarke, H.C., Farnsworth, K.D., Hatcher, M.J., Ennis, M., Kelly, A., Dunn, A.M., 2010. Parasitism may enhance rather than reduce the predatory impact of an invader. Biology Letters 6, 636-638.

Dunn, A.M., 2009. Parasites and biological invasions. Advances in Parasitology 68, 161-184.

Eveleigh, E.S., Chant, D.A., 1982. Experimental studies on acarine predator-prey interactions: the effects of predator density on prey consumption, predator searching efficiency, and the functional response to prey density (Acarina: Phytoseiidae). Canadian Journal of Zoology 60, 611-629. 
Fathipour, Y., Hosseini, A., Talebi, A., Moharramipour, S., 2006. Functional response and mutual interference of Diaeretiella rapae (Hymenoptera: Aphidiidae) on Brevicoryne brassicae (Homoptera: Aphididae). Entomologica Fennica 17, 90-97.

Freedman, H.I., Waltman, P., 1985. Persistence in a model of three competitive populations. Mathematical Biosciences 73, 89-101.

GraphPad Prism, 1999. Analyzing Data with GraphPad Prism version 3, GraphPad Software Inc, San Diego CA, www.graphpad.com.

Grevstad, F.S., Klepetka, B.W., 1992. The influence of plant architecture on the foraging efficiencies of a suite of ladybird beetles feeding on aphids. Oecologia 92: 339-404.

Hassell, M.P., 1971. Mutual interference between searching insect parasites. Journal of Animal Ecology 40, 473-486.

Hassell, M.P., 1978. The Dynamics of Arthropod Predator Prey Systems. Monographs in Population Biology, 13. Princeton University Press, Princeton, NJ, 237pp.

Hassell, M.P., Varley, G.C., 1969. New inductive population model for insect parasites and its bearing on biological control. Nature 223, 1133-1137.

Hatcher, M.J., Dick, J.T.A., Dunn, A.M., 2008. A keystone effect for parasites in intraguild predation? Biology Letters 4, 534-537.

Hodek, I., Honĕk, A., 1996. Ecology of Coccinellidae. Kluwer Academic Publishers, Dordrecht, Netherlands, 464pp.

Kajita, Y., Evans, E.W., 2010. Relationships of body size, fecundity, and invasion success among predatory lady beetles (Coleoptera: Coccinellidae) inhabiting alfalfa fields. Annual review of Entomological Society of America 103, 750-756. 
Koch, R.L., Hutchison, W.D., Venette, R.C., Heimpel, G.E., 2003. Susceptibility of immature monarch butterfly, Danaus plexippus (Lepidoptera: Nymphalidae: Danainae), to predation by Harmonia axyridis (Coleoptera: Coccinellidae). Biological Control 28, 265270.

Lafferty, K.D., 1992. Foraging on preys that are modified by parasites. The American Naturalist $140,854-867$.

Lotka, A.J., 1925. Elements of Physical Biology. Williams \& Wilkins Co., Baltimore, MD.

Ma, L., Lin, T., 2001. Study on the biological characteristics of Homalotylus flaminius. Journal of Forest Research 12, 269-270.

Majerus, M.E.N., 1994. Ladybirds. Hopper Collins, London, 367pp.

Matter, M.M., Mahasen, M.A., Farag, E.N.A., Gesraha, M.A., 2011. Impact of temperature and prey density on the predacious capacity and behaviour of Stethorus punctillum Weise. Archives of Phytopathology and Plant Protection 44, 127-134.

Michaud, J.P., 2012. Coccinellids in biological control. In: Hodek, I., van Emden H. F., Honěk, A. (Eds.), Ecology and Behaviour of the Ladybird Beetles, pp. 488-519. Wiley-Blackwell, West Sussex, UK.

Nicholson, A.J., Bailey, V.A., 1935. Balance of animal populations. Proceedings of the Royal Society, London Part I. pp 551-598.

Novin, M., Mossadegh, M.S., Nejad, M.K., Nejad, M.G., 2000. Natural enemies of Nipaecoccus viridis in the North of Khuzestan. In: Proceedings of the $14^{\text {th }}$ Iranian Plant Protection Congress, p. 264. Isfahan 2000, University of Technology, Iran.

Pasteels, J.M., 2007. Chemical defence, offence and alliance in ants-aphids-ladybirds relationships. Population Ecology 49, 5-14. 
Pervez, A., Omkar, 2005. Functional responses of coccinellid predators: an illustration of logistic approach. Journal of Insect Science 5:5. Available online: www. insectscience.org/5.5.

Poprawski, T.J., Legaspi, J.C., Parker, P.E., 1998. Influence of entomopathogenic fungi on Serangium parcesetosum (Coleoptera: Coccinellidae), an important predator of whiteflies (Homoptera: Aleyrodidae). Environmental Entomology 27, 785-795.

Rubtsov, I.A., 1954. Citrus pests and their natural enemies. Izd. AN SSSR, Moscow-Leningrad (Russia). 260 pp.

Santos-Cividanes, T.M., dos Anjos, A.C.R., Cividanes, F.J., Dias, P.C., 2011. Effects of food deprivation on the development of Coleomegilla maculata (De Geer) (Coleoptera: Coccinellidae). Neotropical Entomology 40, 112-116.

Sarmento, R.A., Pallini, A., Venzon, M., Souza, F.F., Molina-Rugama, A.J., Oliveira, C.L., 2007. Functional response of the predator Eriopis connexa (Coleoptera: Coccinellidae) to different prey types. Brazilian Archives of Biology and Technology 50, 121-126.

Shi, Z., Liu, S., Li, Y., 2002. Cotesia plutellae parasitizing Plutella xylostella: host-age dependent parasitism and its effect on host development and food consumption. BioControl 47, 499-511.

Skirvin, D.J., Perry, J.N., Harrington, R., 1997. The effect of climate change on an aphidcoccinellid interaction. Global Change Biology 3, 1-11.

Slansky, F., Scriber, J.M., 1985. Food consumption and utilization. In: Kerkut, G. A. and L. I. Gilbert (eds.) Comprehensive Insect Physiology, Biochemistry and Pharmacology, vol. 4, pp 87-163. Pergamon Press, Oxford. 
Tranfaglia, A., Viggiani, G., 1972. Dati biologici sullo Scymnus includens Kirsch (Coleoptera: Coccinellidae). [Biological data on Scymnus includens Kirsch (Coleoptera: Coccinellidae)]. Boll Lab Entomol Agr "Filippo Silvestri” Portici 30: 9-18.

van der Meer, J., Ens, B.J., 1997. Models of interference and their consequences for the spatial distribution of ideal and free predators. Journal of Animal Ecology 66, 846-858.

van Emden, H.F., Harrington, R., 2007. Aphids as Crop Pests. CABI International, Oxford shire U.K.

Volterra, V., 1926. Variazioni e fluttuazioni del numero d'individui in specie animali conviventi. Memorie della Accademia Nazionale dei Lincei Ser VI, vol. 2.

Wilmers, C.C., Post, E., Peterson, R.O., Vucetich, J.A., 2006. Predator disease out-break modulates top-down bottom-up and climatic effects on herbivore population dynamics. Ecological Letters 9, 383-389.

Wright, H.A., Wootton, R.J., Barber, I., 2006. The effect of Schistocephalus solidus infection on meal size of three spined sticklebacks. Journal of Fish Biology 68, 801-809.

Fallahzadeh, M., Shojaei, M., Ostovan, H., Kamali, K., 2006. The first report of two parasitoid wasps on the larvae of Nephus bipunctatus (Col., Coccinellidae) from Iran. Journal of Entomological Society of Iran 26, 65-96.

Noyes, J. S., 2005. Universal chalcidoid database. The Natural Histroy Museum (online). Available on: http://www.nhm.ac.uk/entomology/chalcidoids; London/UK

Northfield, T.D., Snyder G. B., Ives A.R., Snyder, W.E., 2010. Niche saturation reveals resource partitioning among consumers. Ecology Letters 13, 338-348 


\section{Table 1.}

Prey consumption of parasitized and unparasitized fourth-instar $N$. includens at various predator densities during a $24 \mathrm{~h}$ period of foraging for $852^{\text {nd }}$ and $3^{\text {rd }}$ instar A. gossypii on a guava leaf in a $9.0 \mathrm{~cm}$ Petri dish.

\begin{tabular}{|c|c|c|c|c|c|c|c|c|}
\hline \multirow{2}{*}{$\begin{array}{c}\text { Predator } \\
\text { density }\end{array}$} & \multicolumn{4}{|c|}{ Number of prey consumed $^{\dagger}$} & \multicolumn{4}{|c|}{ Prey consumption per predator ${ }^{\dagger}$} \\
\hline & unparasitized $^{* * *}$ & parasitized $^{* *}$ & $t$-test ${ }^{\ddagger}$ & $\mathrm{P}$ & unparasitized $^{* * *}$ & parasitized $^{* * *}$ & $t$-test $t^{+}$ & $\mathrm{P}$ \\
\hline 1 & $63.00 \pm 8.45^{\mathrm{b}}$ & $.14^{\mathrm{b}}$ & 5.17 & .0001 & $63.00 \pm 8.45^{\mathrm{a}}$ & $46.11 \pm 3.14^{\mathrm{a}}$ & 5.17 & $<.0001$ \\
\hline 2 & & $49.00 \pm 2.07^{\mathrm{ab}}$ & 6.53 & $<.0001$ & $34.29 \pm 3.52^{\mathrm{b}}$ & $24.50 \pm 1.04^{\mathrm{b}}$ & 6.53 & $<.0001$ \\
\hline 3 & $.09^{\mathrm{a}}$ & $49.43 \pm 1.39^{\mathrm{ab}}$ & 9.2 & $<.0$ & $25.52 \pm 2.36^{\mathrm{c}}$ & $16.48 \pm 0.47^{\mathrm{c}}$ & 9.17 & $<.0001$ \\
\hline 4 & $81.70 \pm 4.19^{\mathrm{a}}$ & $51.57 \pm 3.02^{\mathrm{a}}$ & 15.29 & $<.0001$ & $20.43 \pm 1.05^{\mathrm{d}}$ & $12.89 \pm 0.75^{\mathrm{d}}$ & 10.6 & $<.0001$ \\
\hline 5 & $80.83 \pm 3.98^{\mathrm{a}}$ & $51.86 \pm 2.70^{\mathrm{a}}$ & 14.31 & $<.0001$ & $16.17 \pm 0.79^{\mathrm{d}}$ & $10.37 \pm 0.54^{\mathrm{e}}$ & 14.31 & $<.0001$ \\
\hline
\end{tabular}

\footnotetext{
${ }^{* * * *} \mathrm{P}<0.0001$

${ }^{* *} \mathrm{P}<0.001$

${ }^{\dagger}$ Means \pm SE followed by the same upper case letters are not significantly different according to Tukey's test. ${ }^{\ddagger}$ The levels of probability of significance $(\mathrm{P})$ across rows are indicted according to the $t$-test.
}

Table 2.

Prey consumption of parasitized fourth instar N. includens larvae at various densities of predator and prey $\left(2^{\text {nd }}\right.$ and $3^{\text {rd }}$ instar $A$. gossypii on a guava leaf) during a 24 h period of foraging in a 9.0 cm Petri dish.

\begin{tabular}{|c|c|c|c|}
\hline \multirow{2}{*}{$\begin{array}{c}\text { Predator } \\
\text { density }\end{array}$} & \multicolumn{3}{|c|}{ Number of prey consumed } \\
\hline & 70 nymphs/patch ${ }^{*}$ & 85 nymphs/patch ${ }^{* * *}$ & 100 nymphs/patch ${ }^{* * *}$ \\
\hline $1^{* * * * *}$ & $41.67 \pm 1.69^{\mathrm{C}} \mathrm{b}$ & $46.11 \pm 3.14^{\mathrm{B}} \mathrm{b}$ & $50.50 \pm 1.89^{A}{ }_{c}$ \\
\hline $2^{* * * *}$ & $46.50 \pm 1.71_{\mathrm{a}}^{\mathrm{C}}$ & $49.00 \pm 2.07_{\mathrm{a}}^{\mathrm{B}}$ & $55.50 \pm 3.09^{\mathrm{A}}{ }_{\mathrm{b}}$ \\
\hline $3^{* * *}$ & $46.67 \pm 1.79^{C}{ }_{a}$ & $49.43 \pm 1.39^{\mathrm{B}}{ }_{\mathrm{a}}$ & $58.67 \pm 1.97_{\mathrm{a}}^{\mathrm{A}}$ \\
\hline $4^{* * *}$ & $47.00 \pm 2.31_{\mathrm{a}}^{\mathrm{C}}$ & $51.57 \pm 3.02^{\mathrm{B}}{ }_{\mathrm{a}}$ & $60.33 \pm 2.21_{\mathrm{a}}^{\mathrm{A}}$ \\
\hline $5^{* * *}$ & $46.17 \pm 2.91^{\mathrm{C}}{ }_{\mathrm{a}}$ & $51.86 \pm 2.70_{a}^{B}$ & $61.83 \pm 2.27^{\mathrm{A}}{ }_{\mathrm{a}}$ \\
\hline $\mathrm{P}<0.0001$ & & & \\
\hline${ }_{*}^{*} \mathrm{P}<0.001$ & & & \\
\hline & & & \\
\hline
\end{tabular}

Means \pm SE within each row (i.e., between prey densities) followed by the different capital letters (upper case) and within each column followed by the different small letters (lower case) are significantly different according to Tukey's Test. 


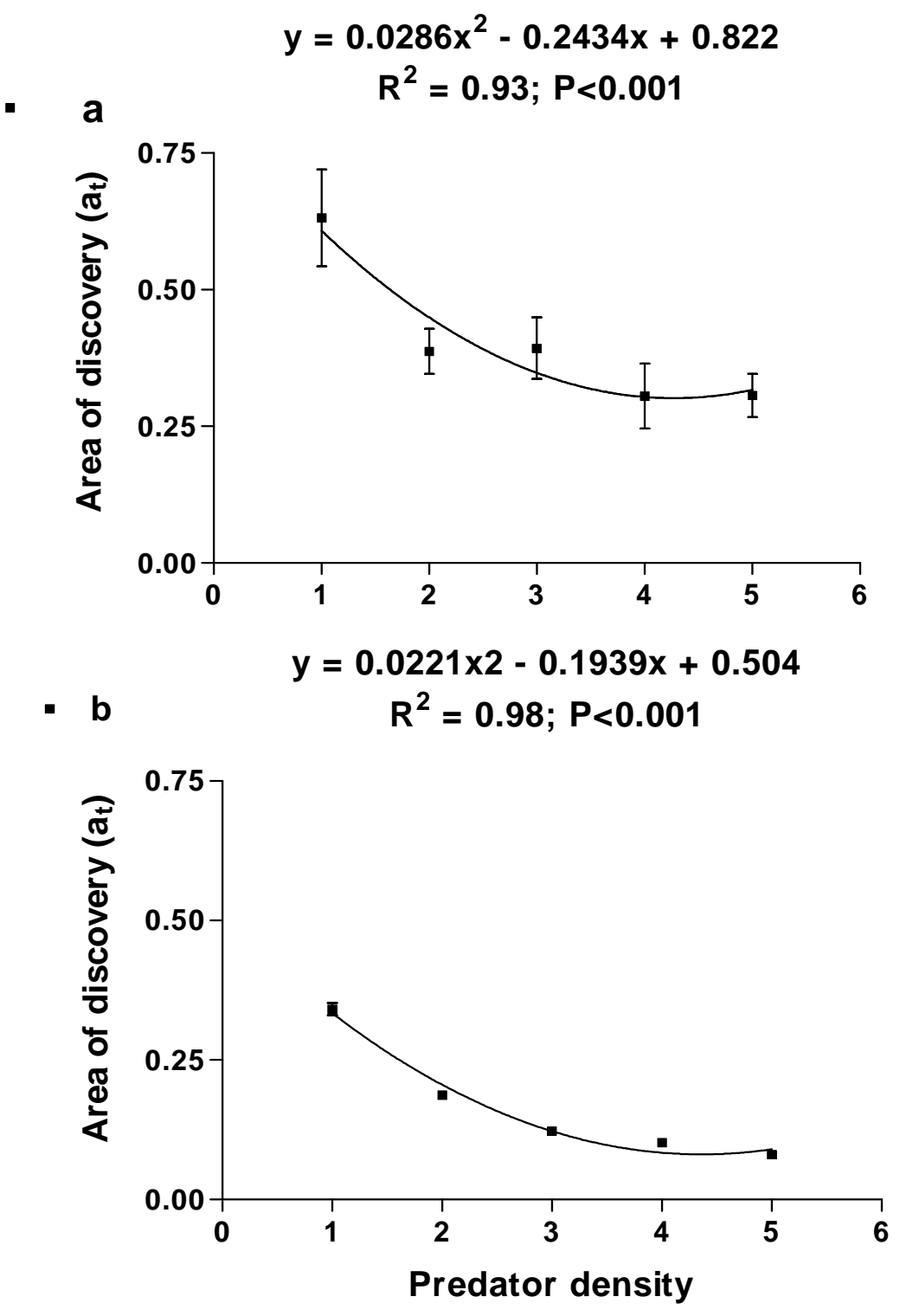

\section{Figure 1}

Fig. 1. Relationship between area of discovery and predator density of (a) unparasitized and (b) parasitized fourth instar larvae of $N$. includens during a $24 \mathrm{~h}$ period of foraging for aphids $\left(852^{\text {nd }}\right.$ and $3^{\text {rd }}$ instar A. gossypii on a guava leaf) in a $9.0 \mathrm{~cm}$ Petri dish. 


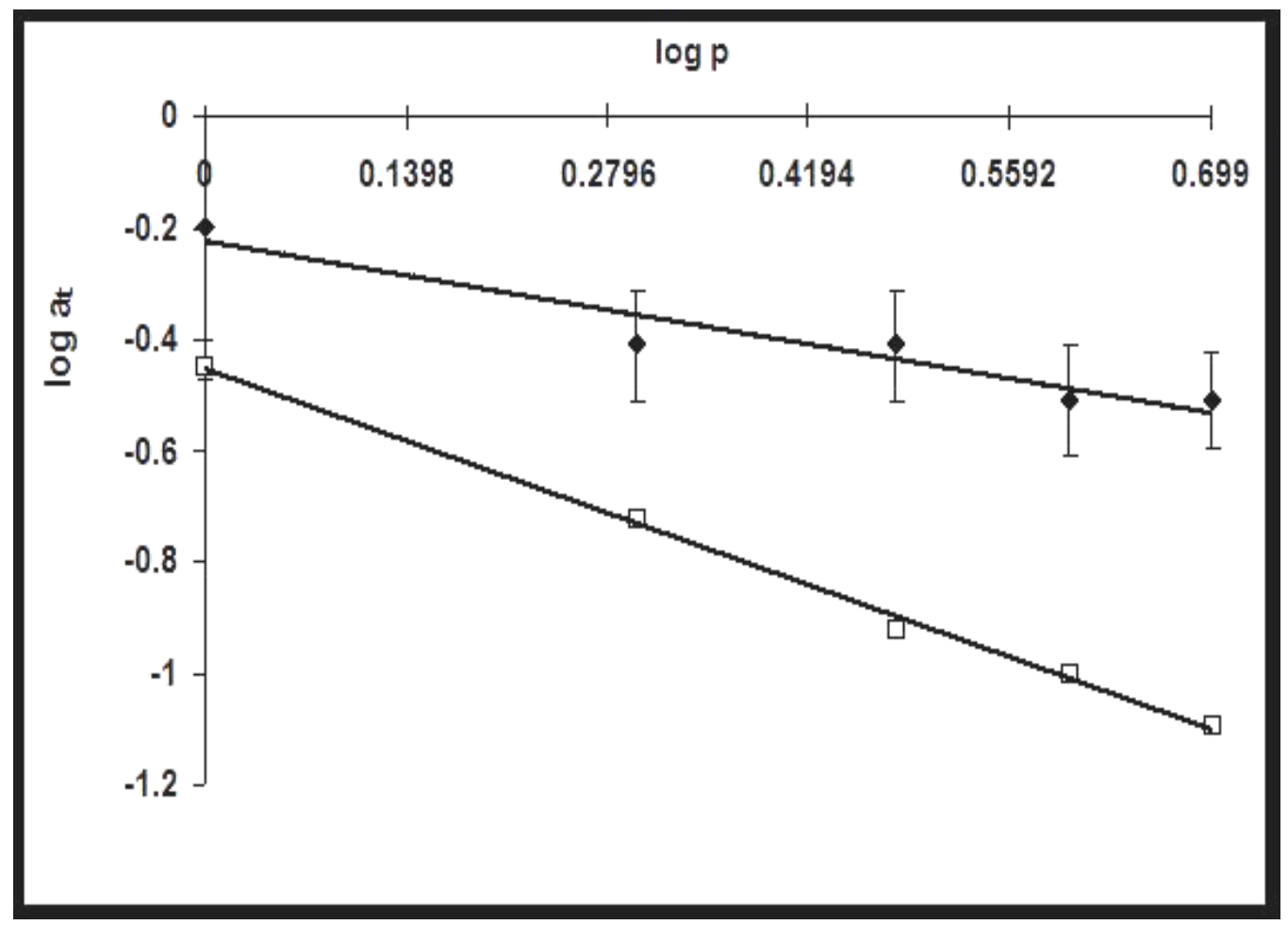

Figure 2

Fig. 2. Interference derived from the relationship between logarithm of predator density (P) and area of discovery $\left(\mathrm{a}_{\mathrm{t}}\right)$ of the unparasitized $(\square)$ and parasitized $(\triangleleft)$ fourth instars of $N$. includens during a $24 \mathrm{~h}$ period of foraging for aphids ( $852^{\text {nd }}$ and $3^{\text {rd }}$ instar $A$. gossypii on a guava leaf $)$ in a $9.0 \mathrm{~cm}$ Petri dish $\left(\log _{\mathrm{at}}=-0.45-0.92 \log \mathrm{P}, \mathrm{r}^{2}=0.99, \mathrm{P}<0.001\right.$ and $\log _{\mathrm{at}}=-0.23-0.44 \log \mathrm{P}, \mathrm{r}^{2}=0.92$, $\mathrm{P}<0.001$, respectively). 


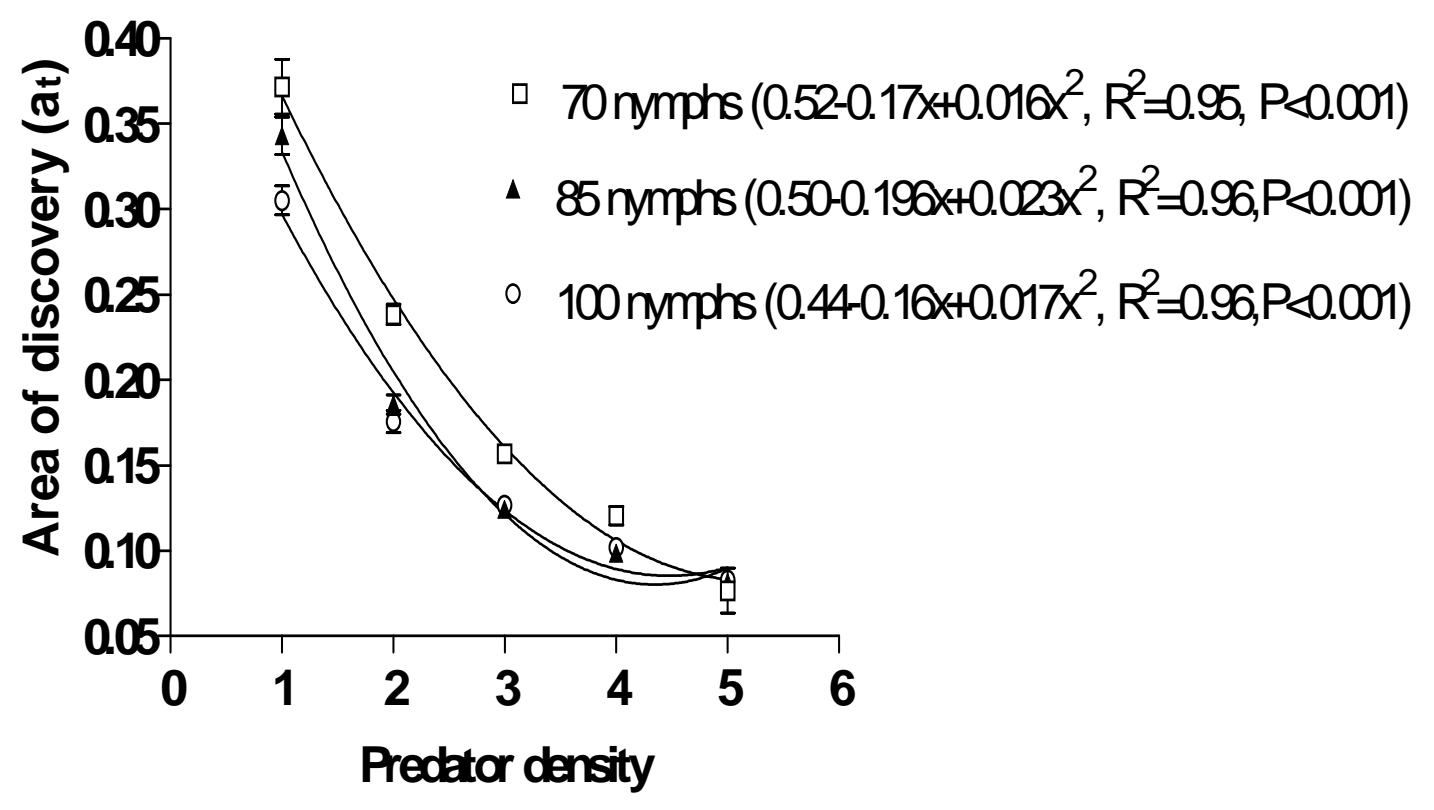

Figure3

Fig. 3. Relationship between area of discovery and predator density for parasitized fourth instar $N$. includens during a $24 \mathrm{~h}$ period foraging for various densities of prey $\left(2^{\text {nd }}\right.$ and $3^{\text {rd }}$ instar $A$. gossypii on a guava leaf) in a $9.0 \mathrm{~cm}$ Petri dish. 


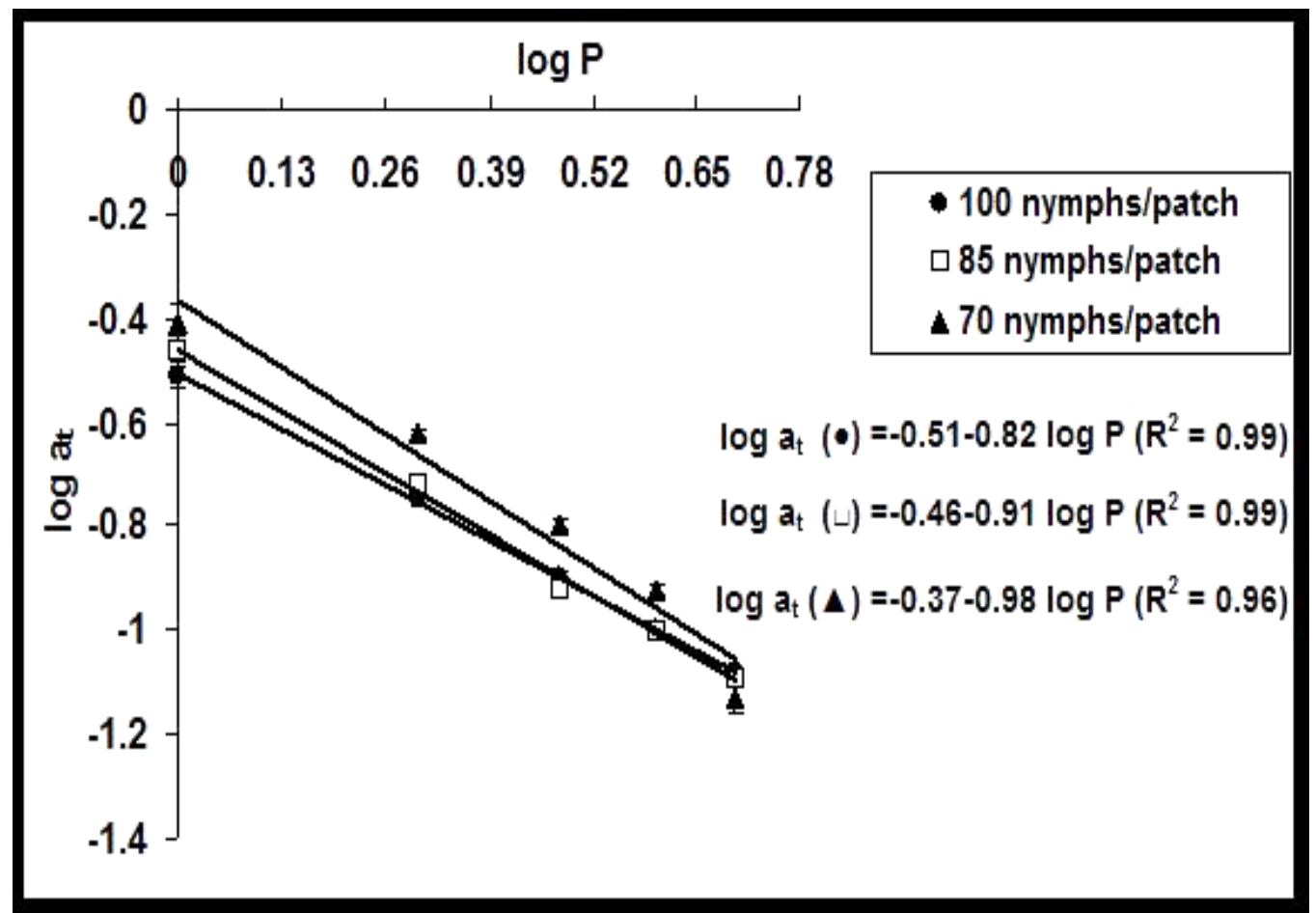

Figure 4

Fig. 4. Interference derived from the relationship between the logarithm of predator density (P) and the area of discovery $\left(\mathrm{a}_{\mathrm{t}}\right)$ for parasitized fourth instar $N$. includens larvae during a $24 \mathrm{~h}$ period of foraging at various densities of prey $\left(2^{\text {nd }}\right.$ and $3^{\text {rd }}$ instar A. gossypii on a guava leaf $)$ in a $9.0 \mathrm{~cm}$ Petri dish. 